\title{
Deficiencia de $\lg A$
}

DR. RICARDO SORENSEN D. *

La deficiencia de IgA es la más frecuente de las alteraciones de inmunidad humoral. Se puede encontrar en personas aparentemente normales, en frecuencias que varían desde 1 en 700 a 1 en 3.000 a más, según distintas encuestas. Además, esta deficiencia se encuentra asociada a las más variadas condiciones patológicas, que se pueden agrupar en 1) Ataxia-telangectasia, 2) infecciones respiratorias y de tracto digestivo, 3) Hipersensibilidad (atopía), 4) Sprue asociado a deficiencia de IgA, 5) mesenquimopatías (lupus y artritis reumatoidea) 6) Hiperplasia linfática y tumores, particularmente limfontas, 7) hemosiderosis pulmonar y neumonía descamativa intersticial, hepatitis crónica, tiroiditis, panencefalitis, anemia hemolítica antoinmune, etc. $(1,2,3,4,5,6,7,8,9,10)$.

El objeto de la presente comunicación es llamar la atención sobre esta alteración de la respuesta inmune presentando una casuística de 6 pacientes estudiados por nosotros, y que ilustran la variedad de condiciones patológicas relacionadas con deficiencias de $\operatorname{IgA}$. Sólo se ha incluido los casos en que esta deficiencia cra severa, y se encontró en varios controles. La posibilidad de que deficiencias de menor intensidad contribuyan también a causar infecciones a repetición y reacciones de hipersensibilidad será discutida en otra presentación en está revista (11).

Los de nuestros pacientes, que hemos estudiado en detalle, scrán presentados in cxtenso, analizando sus manifestaciones clínicas y de laboratorjo en base a un modelo de la respuesta inmune en el arbol respiratorio presentada en otro trabajo, (12).

Presentación de casos clínicos. Los hallazgos más importantes en los 6 pacientes analizados se han resumido en la tabla No 1 . El denominador común está dado por una severa disminución de IgA no acompañada de deficiencia de otras inmunoglobulinas, salvo en el caso No 6 que será discutido en detalle. Los valores de inmunoglobulinas están expresados en este cuadro en Unidades Internacionales (13).

TA B L A No 1

RESUMEN DE G CASOS DE DEFICIENCIA IgA.

\begin{tabular}{|c|c|c|c|c|c|}
\hline Pociente & Edad & Diagnóstico & $\operatorname{IgG} U I$ & IgMUl & $\lg A U 1$ \\
\hline 1) M S Y 197 & $3 \mathrm{~m}$ & Desnutrición & 208 & 150 & 2 \\
\hline $\begin{array}{l}\text { 1) M. S. V197 } \\
\text { 2) S. A. CM56 }\end{array}$ & 3 a. & $\begin{array}{l}\text { Monnlasis cutaneal } \\
\text { Histiocitosis } \mathrm{X}\end{array}$ & 276 & $\begin{array}{r}150 \\
96\end{array}$ & $<1$ \\
\hline 3) M. V. V157 & 13 a. & Linfoma & 156 & 124 & 5 \\
\hline 4) P. L. V49 & $14 \mathrm{a}$. & Bronquitis a repetición & 344 & 40 & 5 \\
\hline 5) A. M. CM52 & $9 \mathrm{a}$. & Artritis Reumatoidea & 240 & 184 & $<1$ \\
\hline 6) M. M. T9 & 9 a. & Infecciones a repeticion & 28 & 130 & $<1$ \\
\hline
\end{tabular}

* Unidad de Inmunologia. Depto. Paciatría, Aren Oriente, Hospital Calvo Mackenna. Sección Inmunopatología, Instituto Bacterioliggien de Chilc. 
A. M. Paciente No 5: Sexo femenino, actualmente 8 años de cdad.

Antecedentes familiares. Abuelo materno con lesiones cutáncas en mejillas de aparición fuzaz. Padre sano. Madre operada de cáncer ginetológico hace un año. 5 hijos vivos sanos. Uno tallecido en periodo de RN, ignoran causa. Grupo familiar en buena situación socioeconómica.

Antecedentes personales. Nacida de parto de término el 23-Vi-1964. Peso de nacimiento 2.300 grs. Alimentación adecuada. Ha recibido vacunas $B C G$, mixta y Sabin dos dosis, sarampión y antivariólica, sin presentar reacción a ninguna de ellas. El test de PPD realizado en varias oporturidades fue (-).

Enfermedad actual. Durante los dos primeros años de edad, diarrea y bronquitis a repetición. Posteriormente, frecuentes episodios de fa. ringitis y amigdalitis que a la edad de 6 años motivan la amigdelectomía y adenoidectomía. Des. pués de la intervenciôn quirúrgica comenzó a presentar aumento de volumen de la nariz y mejillas con rubor, dolor, vesiculación y rodete. De estas lesiones se aisló estreptococos $\mathbf{B}$ hemolítico por lo que se trató con penicilina, con buenos resultados. La mencionada lesión r ccidivó en numerosas opor. tunidades acompañada de fiebre, anorexia, decaimiento lo que indujo a innumerables esquemas terapéuticos con diversos antibióticos: sulfas, penicilina o critromicina, con resultados positivos por breves periodos de tiempo. Hace un año se agregan poliartralgias de manos, caderas, rodillas, tobillos que le producen claudicación de la deambulación. Ocasionalmente artritis en ambas rodillas. Vista por médico en momentos en que predominaban las artralgias y un leve compromiso cardía$c o, c o n$ antecedentes de una erisipela reciente, diagnostica Enfermedad Reumática, iniciando tratamiento con penicilina, aspirina y reposo en cama por 6 meses. La VHS estaba elevada y el título de antiestreptolisina elevado (500 Todd). Fue dado de alta sin compromiso cardiaco.

En los últimos meses del año 1971 presentó numerosas recaídas con manifestaciones cutáneas, articulares y alzas febriles hasta $40^{\circ} \mathrm{C}$. con compromiso del estado general y VHS elevadas. Todas estas manifestaciones desaparecían espontáneamente.

En la tabla N" 2 se resumen los principales hallazgos en este paciente. Efcetuados los exámenes allí anotados se concluye que se trata de una deficiencia de IgA acmpañada de una artritis reumatoidea juvenil, que ha permanecido asintomática en los últimos meses, de manera que no ha requerido tratamiento. Se indicó uso de antibióticos de amplio espectro frente a infecciones sin espera una evolución favorable espontánea.
TA B L A N 2

RESUMEN EXAMENES PACIENTE 5: A. M.

DEFENSAS INESPECIFICAS:

Neutrofilos (seriados) normales.

Complemento normal.

INMUNIDAD CELULAR:

Livfocitos (seriados) normales

reacción normal a vacuna $\mathrm{BCG}$.

\section{INMUNIDAD HUMORAL:}

JgG (promedio 3 determinaciones) ... 250 U.I.

IgM (promedio 3 determinaciones) ... 152 U.I.

IgA (promedio 3 determinaciones) .... $<1$ U.I.

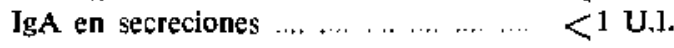

IgE (test cutáneo) $\ldots \ldots \ldots \ldots \ldots$. . . . . . .

lsoaglutininas normales.

FENOMENOS AUTOINMUNIDAD:

Células LE: Tepetidamente negativos.

Anticuerpos anti-nucleares: negativos, ocasionalmente positivos.

Factor Reumatoideo: positivo 1:60 y 1:80 (lálex).

INMUNOGLOBULINAS EN PADRES

$Y$ HERMANOS;

Normales.

M. M. Paciente No 6: Sexo Masculino, actualmentc 8 años de cdad.

Antecedentes familiares. Padres sanos. I hermano fallecido por diarrea a los 23 meses de cdad, 1 hermano mayor con amigdalitis a repetición hasta los 8 años edad, actualmente sano. 2 primos maternos de sexo masculino y de sexo feincnino, presentan infecciones a repetición, pero no han podido ser estudiados.

Antecedentes personales. Nacido de parto de término en Octubre de 1964. Embarazo normal. Recibió esquema normal de vacunaciones, sin reacciones adversas. Cicatriz BCG normal.

Entre el $2^{\circ}$ y $6^{\circ}$ año de vida presenta gran número de infecciones, prinando las infecciones de la vía respiratoria superior y episodios diarreicos. Esto motivó la administración de antibióticos en incontables ocasiones: el último año antes de ser diagnosticado recibió 15 veces antibió ticos de uso general, y de uso tópico en 9 ocasio nes. Hace 4 años se diagnosticó una hipogamaglobulinemia en la electroforesis en papel y luego una deficiencia de $\operatorname{IgA}$ sérica y secretada acompañada de una deficiencia relativa de IgG (Que causa la 
disminución de las gamaglobulinas en la electroforesis en papel).

Por prescntar una deficiencia de IgG se inicia un tratamiento con $100 \mathrm{mg}$. de gamablobulina por kilo de peso en dosis mensuales, $(0,6 \mathrm{ml}+\mathrm{Kg}$.) que se manticne hasta la fecha. Con esta dosis, que no se ha retsejado en un aumento de los niveles séricos de igG̈, el niño ha evolucionado favorablemente hasta la fecha. Ha presentado un promedio de 3 a 5 cuadros febriles al año, en general con manifestaciones de bronquitis o de infección abdominal, que han cedido en los plazos usuales al ser tratados con antibióticos de amplio espectro. El tercer año de tratamiento presentó durante 2 meses una coriza purulenta rebelde al tratamiento con diversos antibióticos según antibiogramas, y que no se ba vuelto a repetir. Actualmente lleva una vida normal. El último año ha presentado sólo 2 cuadros febriles catalogados como gripe, que cvolucionaron sin complicaciones a pesar de no haber variado su deficiencia de inmunoglobulinas $G$ y $A$.

Los niveles de inmunoglobulinas de los familiares de este paciente se resumen en la tabla No 3. Destaca que un hermano aparentemente sano tenga valores persistentemente bajos de $\operatorname{IgA}$. Los principales hallazgos de laboratorio se han anotado en la tabla No 4 y la evolución de los niveles de inmunoglobulinas en un período de más de dos años se pueden observar en el gráfico Nọ 1 .

Comentario. En la actualidad no se conocen exactamente los mecanismos por los cuales la deficiencia de IgA lleva a la producción de patolo-
TA B L A N? 3

ANTECEDENTES FAMILIARES-PACIENTE $5 \mathrm{M}$. M.

\begin{tabular}{l|r|r|r}
\hline & $I g G$ & $I g M$ & $I g A$ \\
\hline 1 padre & 740 & 250 & 309 \\
2 madre & 1.000 & 240 & 159 \\
*3 hermano & - & - & - \\
**4 hermano & 1.060 & 204 & 50 \\
\hline
\end{tabular}

* Fallecido a los 23 meses de edad.

* * Promedio de 3 determinaciones, con 3 meses de diferencia.

T A B L A No 4

RESUMEN EXAMENES PACIENTE $6 \mathrm{M}$. $M$.

DEFENSAS INESPECIFICAS:

Neutrófilos (seriados): normales.

Fagocitosis: Normal.

C Hemolítico: Normal.

C3 (seriado): Normal.

INMUNIDAD CELULAR:

Linfocitos (seriados): normales

INMUNYOAD HUMORAL:

Isoaglutininas anti-B: ausentes

IgA en saliva: ausente.

IgA en liquido sinual: ausente

IgE (test cutáneo) ausente.

\section{BASE HISTOLOGICA:}

Adenoides de mucosa nasal con estructura linfática conservada. Ausencia de plasmocitos en los folículos.

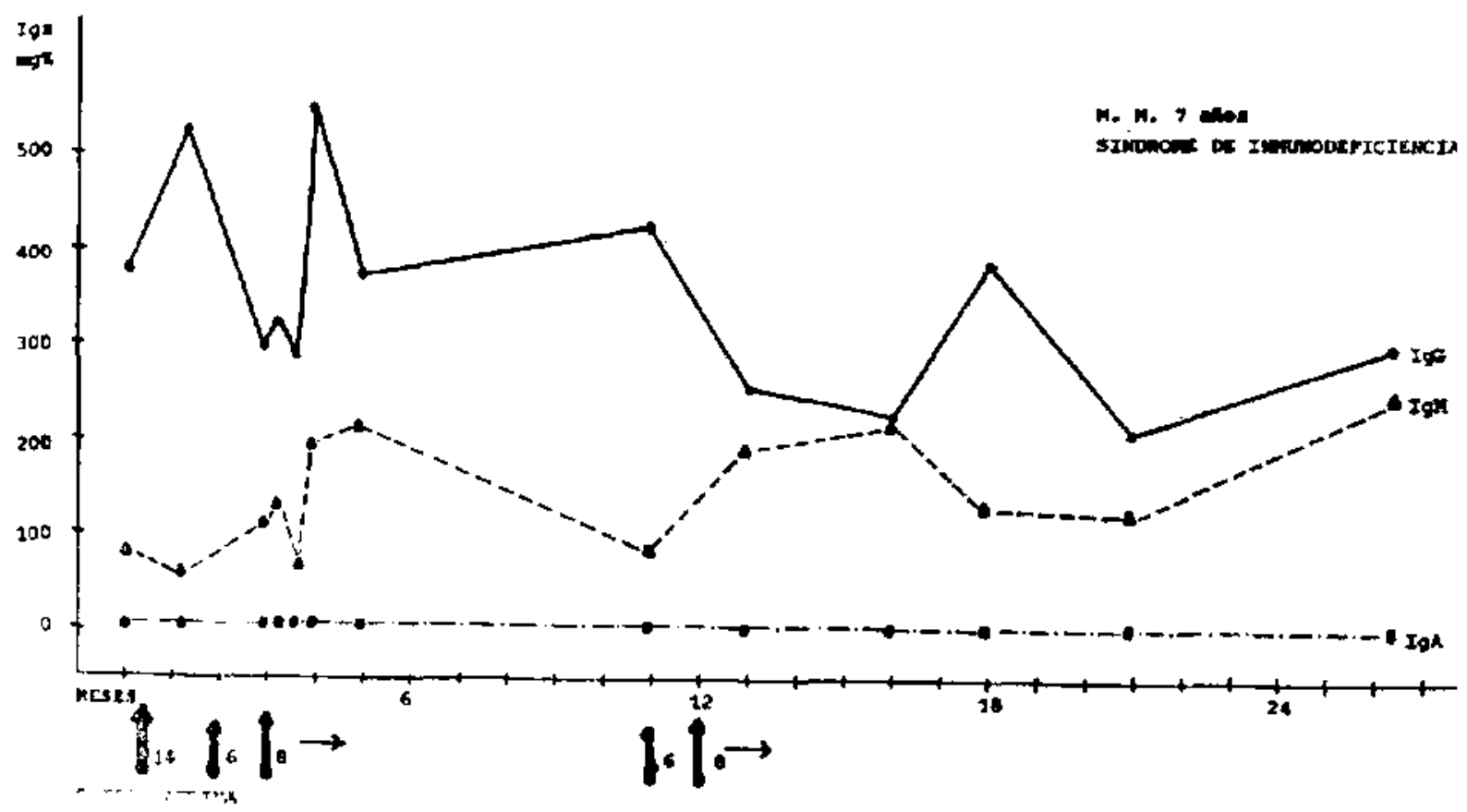

Gráfico No 1,- Evolución de los niveles de inmunoglobulinas del paciente Niّ 6. MM. 
gías tan variables como las resumidas en la introducción, y las cuates se ven incrementadas por un caso de histiocitosis en nuestra casuistica.

La JgA no capta complemento. Esto permite que pucda neutralizar un antigeno sin causar las reacciones lisulares condicionadas por la acción del complemento. Sin embargo, la unión con el antígeno es suficiente para prevenir la posibilidad de que esto induzea una respuesta inmune más "atrás", del tipo IgE o IgG. Ese es un posible mecanismo que permite explicar la relación entre ausencia de lgA e hipersensibilidad. Su ausencia igualmente facilita el acceso de virus al organismo. Estos virus a su vez podrían ser responsables de la inducción de tumores o de fenómenos de autoinmunidad. Por último, el ingreso masivo de antigenos contenidos en los alimentos (proteínas de la leche por ejemplo) condiciona respuestas inmune en el sistema IgG (precipitinas anti-leche) que podrían ser responsables de los casos de enfermedad celíaca y sprue asociados a deficiencia de IgA.

En la paciente A. M. (No 5) la única alteración inmunológica detectable es una deficiencia de IgA, junto a la aparición de automnticuerpos (factor reumatoideo y anticuerpos antinucleares).

Tiene una reacción normal de IgE cutánea, que si bien no da una información cuantitativa, permite afirmar que ticne IgE, y que no es especialmente sensible a reacciones de hipersensibilidad inmediata (tipo I). Esto podría explicar que clínicamente en ella no se ven cuadros infecciosos de vias respiratorias a tracto digestivo, $y$ que tampoco presenta manifestaciones de hipersensibilidad inmediata a nivel del árbol respiratorio o piel (14).

Lás manifustaciones cutáneas de la cara pueden atribuirse a una erisipela, que si bien durante un período prolongado tuvo tendencia a recidivar, siempre respondió bien cuando se trató con un antibiótico adceuado. Esta mayor susceptibilidad podría tener relación con la deficiencia de IgA en la mucosa nasal, aun cuando deben postularse la participación de otros factores que contribuyan a uла menor resistencia frente a infecciones. Entre estos pueden consignarse la tonsitectomia y adenoidectomia, en la cual se retira una cantidad importante de tejido linfático, en una paciente con respuesta innune ya alterada genéticamente.

La causa de la artritis reumatoidea no se conoce, aun cuando se postula un desencadenamiento por un agente infeccioso con especial tropismo por el teijido sinovial. Desconociendo la naturaleza de ésta, se hace también difícil interpretar el papel predisponente que pueda jugar la deficiencia de IgA. Por el momento, éste puede postularse como una deficiente barrera a la penetración de un probable agente infeccioso.

El paciente $M, M$. (No 6) es muy interesante por cuanto tiene una deficiencia humoral compuesta: ausencia de lgA e IgE, deficiencia parcial de IgG e IgM normal. A pesar de esto último, no es capaz de sintetizar iso anticuerpos anliB (su grupo sanguíneo cs ORh $(+)$, lo que apunta además hacia una incapacidad de respuesta específica para determinados antígenos. En este pacicnte fallan las barreras frente a agentes infecciosos y alérgicos (IgA secretada), pero al no tener IgE en las mucosas, tampoco presenta fenómenos de hipersensibilidad inmediata. Esta misma difeciencia de IgE, junto a una menor cantidad de IgG, puede sindicarse como causante de una mayor sensibilidad a infecciones. Podria además proponerse que su incapacidad de responder también con formación de IgG y en algunos casos con IgM lo protege de fenómenos de autoinmunidad como los que presentó la paciente descrita anteriormente.

El tratamiento de este paciente con gamaglobulina, que es una fracción concentrada de suero humano que contiene fundamentalmente IgG, pero que también contiene pequeñas cantidades de IgA e IgM, es discutible. Se inició al conocer los resultados de los electroforesis, que revelaba una hipogamaglobulinemia. Esttictamente, en base a los resultados de la cuantificación de IgG cuyos niveles están en cantidades cercanas al límite minımo inferior $(300 \mathrm{mg} \%)$, no había necesidad de indicar gamaglobulina. Se ha descrito además la aparición de anticuerpos anti-IgA en estos pacientes, que pueden causar reacciones adversas al administrar gamaglobulina (15). Estas no se han observado en nuestro paciente después de 4 años de tratamiento. La administración de gamaglobulina no se ha suspendido por la evolución favorable que ha presentado desde que se inició y por la resistencia de los padres a siquicra reducir la dosis.

\section{RESUMEN}

Se presentan 6 casos de deficiencia de $\operatorname{Ig} A$ en niños, 2 de los cuales se discuten en defalle. Destaca la variedad de la patología asociada a la deficiencia de $\operatorname{Ig} A$, que incluye infecciones a repetición, hipersensibilidad, mesenquimopatias y tumores. En base a los casos observados se discuten los mecanismos por los cuales esta deficiencia puede condicionar la aparición de distintos cuadros clinicos.

\section{SUMMARY}

6 children with IgA deficiency are presented. 2 of them are discussed in detail. The different pathologic conditions associated with this deficiency, including infections, hypersensibility, mesenquimo paties and tumors are pointed out. The mechanisms by which IgA deficien. cy may cause different clinical diseases are discussed. 


\section{Bibliografīa}

1.-Tomasi, T. B. Secretory Immunoglobulins. New. Eng. J. Med. 287: 500, 1972.

2.-Primany Immunodeficiencias. Bull. Wld. Hitla Org. 45: 125, 1971.

3.-Buser, F., Burler, R., and Martin du Pan, R.: Susceptibility to infection and IgA deficiency in the infant. J. Pediatrics 72; 29, 1968.

4.-Tushan, F. S., Zawadzki, Z. A., Vasallo, C. L. and Robin, E. D. Serum IgA deficiency in a man with dcsquamative intesticial pneumonia. Am. Rev. Resp. Dis. 103: 264, 1971.

5.-Gerson, K. L. Haslam, R. H. A.: Subtle immunologic abnormalities in four boys with subacute serosing pancncephalitis. New. Eng. J. Med. 285: $78,1971$.

6.-Kaufman, H. S., and Hobbs, J. R.: Immunoglobulin deficiencies in an atopic population. Iancet, 2: 1061,1970 .

7.-Amman, A. J., and Hong, R.: Selective IgA deficiency and Autoimmunity J. Lab. Clin. Mad. 74; $846,1969$.

8.-Collins-Williams, C., and Lamcja, C.: Deficiency of IgA in Scrum and Respiratory Secretions. Cianad. Med. Ass. J. 99: 1069, 1968.
9.-Ciman, H. N., Meville, D. A., Peakman, D., ahd Robinson, A.: lsolated severe gamina A deficiency: immunoglobulin levels, clinical dissorders, and chromosome studies. J. Lab. Clin. Med. 75: 307, 1970.

10.-Good, R. A., and Rodly, G. E.: IgA Deficiency, antigenic Barriers, and Autoimmunity. Cellulat Immunol. 1; 147, 1970 .

11.-Sorensen, R., Rebolledo, L.: Las enfermedades del árbol respiratorio vistas por $\mathrm{cl}$ inmunólogo. Rev. Chil. Pediatría, en prensa.

12.-Gallegos, H., Rebolledo, L., Burdach, R., Carmona, A., Sorensen, R.: Niveles de IgA en bronquitis obstructiva recidivante en lactantes. Rev. Chil. Pediatría. Vol. 44, No 4. En prensa.

13.-Rowe, D. S., Grab. B., Anderson, S. G.: An international reference preparation for buman serum immunoglobulins G., $A$ and $M$.: content of immuglobulins by weight. Bull. Wld. Hlth. Org. 46: 67. 1972 .

14.-Schwartz, D. P. Buchtey, R. H,: Serum IgE concentrations and skin reativity to anti-IgE antibody in IgA-deficiency patients, Now Eng. J. Med. 284: $513,1971$.

15.-Fudenberg, H., Gold, E. Vyas, G. N, Machenzic, M. R.: Human antibodies to human IgA glubulins. Immunochetnistrv 5: 203, 1968. 